\title{
PENGARUH PENINGKATAN SUHU DAN BESARAN ARUS TERHADAP TAHANAN PENGHANTAR KABEL LISTRIK TEGANGAN RENDAH JENIS NYM
}

\author{
${ }^{1}$ Kiki Rosiana Dewi, ${ }^{2}$ Suyitno, ${ }^{3}$ Nur Hanifah Yuninda \\ 1,2,3 Pendidikan Teknik Elektro, Fakultas Teknik, Univeristas Negeri Jakarta \\ 1,2,3 Email : kikirosianad@gmail.com; suyitno@unj.ac.id ; hanifah@unj.ac.id
}

\begin{abstract}
The purpose of this research is to know about influence of temperature increasing and current rate on the conductor resistance, the conductor temperature and the conductor power losses of the conductors of the cable brand $A$ and brand $B$ due to the effect of increasing temperature and current magnitude. Increasing the temperature and currents rate have a bigger influence on the increase of temperature conductor, the resistance conductor and conductor losses the electric cable brand $B$ compared to the brand $A$. The electricity cable brand $B$ is a conductor that does not have standardization suitable for electrical installation. The conductor of brand $A$ electrical cable is a cable conductor that has standardization and is suitable for use. At chamber temperature of $25{ }^{\circ} \mathrm{C}$ the test current $5 \mathrm{~A}$ the value of conductor resistance $2 \times 1.5 \mathrm{~mm} 2$ of brand A increases by $11,90 \mathrm{~m} \Omega$ while brand $B$ increases by $23.32 \mathrm{~m} \Omega$. The maximum conductor resistance according to standardization is $12,10 \mathrm{~m} \Omega$ for a cross section area of $1.5 \mathrm{~mm} 2$. Based on the test results, each increase in temperature and the currents rate have an influence for increasing value of the conductor temperature, the conductor resistance and conductor losses are bigger. The relationship between the conductor resistance and the cross-sectional area is that the smaller the cross-sectional area, the bigger the conductor resistance.
\end{abstract}

Keyword : Conductor Of NYM Low Voltage Electricity Cable, Temperature of Conductor, Resistance of Conductor, Conductor Losses.

Abstrak
Tujuan dari penelitian ini adalah untuk mengetahui pengaruh peningkatan suhu dan besaran arus terhadap nilai tahanan penghantar, suhu penghantar dan rugi daya penghantar pada penghantar kabel listrik merk A dan merk B. Peningkatan suhu dan besaran arus mempunyai pengaruh yang lebih besar terhadap kenaikan suhu penghantar, tahanan penghantar dan rugi daya penghantar kabel listrik merk B dibandingkan dengan merk A. Penghantar kabel merk B merupakan penghantar yang tidak memiliki standarisasi layak pakai dalam instalasi listrik. Penghantar kabel listrik merk A merupakan penghantar kabel yang telah memiliki standarisasi dan layak pakai. Pada suhu chamber $25^{\circ} \mathrm{C}$ arus pengujian 5 A nilai tahanan penghantar $2 \times 1,5 \mathrm{~mm}^{2}$ merk A meningkat sebesar $11,90 \mathrm{~m} \Omega$ sedangkan merk B meningkat sebesar $23,32 \mathrm{~m} \Omega$. Nilai tahanan penghantar maksimal sesuai dengan standarisasi adalah sebesar 12,10 $\mathrm{m} \Omega$ untuk luas penampang 1,5 $\mathrm{mm}^{2}$. Berdasarkan hasil pengujian, setiap peningkatan suhu dan besaran arus nilai memiliki pengaruh terhadap kenaikan nilai suhu penghantar, tahanan penghantar dan rugi daya penghantar semakin besar. Hubungan antara tahanan penghantar dengan luas penampang yaitu dengan semakin kecil luas penampang maka nilai tahanan penghantar semakin besar.

Kata Kunci: Penghantar Kabel Listrik Jenis NYM, Suhu Penghantar, Tahanan Penghantar, Rugi Daya

Penghantar

\section{PENDAHULUAN}

Penyaluran energi listrik dari sistem pembangkit listrik ke konsumen membutuhkan saluran udara tegangan ekstra tinggi, saluran udara tegangan tinggi, saluran udara tegangan rendah hingga saluran udara tegangan rendah. Sistem tenaga listrik selain di saluran melalui penghantar saluran udara, dapat juga disalurkan melalui penyaluran listrik menggunakan kabel bawah tanah.

Penghantar kabel listrik yang digunakan pada sistem penyaluran listrik tergantung dengan kapasitas arus yang akan mengalir di penghantar tersebut. Salah satu penghantar kabel listrik yang umum dan telah sesuai dengan standar yang ditetapkan adalah kabel. Kabel memiliki beberapa bagian seperti isolasi, penghantar, bahan pengisi, bahan pengikat, beban mekanik, dan selubung pelindung luar. Kasus kebakaran seringkali terjadi dikarenakan karena hubung singkat listrik ataupun karena unjuk kerja perlengkapan listrik yang tidak sesuai dengan standar dan prosedur yang telah ditetapkan. Kemampuan penghantar kabel listrik dalam menghantarkan daya listrik sangat dipengaruhi oleh kualitas penghantar, bahan isolasi, dan tahanannya. Selain hal tersebut, kondisi lingkungan dengan suhu yang bervariasi akan mempengaruhi penghantar, bahan isolasi, dan tahanannya. Selain kondisi suhu lingkungan, kapasitas arus yang mengalir melewati kabel tersebut juga mempengaruhi unjuk kerja pada kabel. Pemanasan pada kabel karena aliran arus listrik dalam kurun waktu tertentu dan pengaruh 
suhu lingkungan yang berubah dapat mengakibatkan nilai tahanan penghantar meningkat sehingga memicu rugi-rugi penghantar dan distribusi daya tidak maksimal. Dalam sistem instalasi listrik, kabel memiliki peranan sangat penting karena fungsinya sebagai perantara untuk menyalurkan energi listrik. Pemilihan kabel yang akan digunakan perlu diperhatikan bahan materialnya, kapasitas arus serta daya tahan termal yang berhubungan dengan meningkatnya tahanan penghantar dan rugi-rugi penghantar. Penggunaan arus yang sesuai pada kabel sangat meminimalisasi kemungkinan kerusakan dan kenaikan suhu yang tinggi pada kabel.

Pada kondisi diatas rating arus maksimum kabel, temperatur kawat mengalami kenaikan yang cukup tinggi dan cenderung tidak stabil. Tetapi semakin besar arus yang diberikan semakin cepat mencapai titik setimbangnya. Ketidakstabilan ini disebabkan karena adanya pemuaian yang terjadi pada kawat penghantar. Dimana pada saat memuai struktur kawat mengalami perubahan yang mengakibatkan daya hantar panas terganggu.

Dengan mengetahui pengaruh peningkatan suhu dan besaran arus terhadap tahanan penghantar kabel listrik tegangan rendah jenis NYM maka diharapkan dapat membantu pemilihan jenis dan penggunaan kabel sesuai dengan kebutuhan.

\section{METODE PENELITIAN}

Metode yang digunakan dalam penelitian ini adalah pendekatan kuantitatif dengan metode penelitian eksperimen. Menurut Sugiyono (2015: 72) metode penelitian eksperimen adalah metode penelitian yang digunakan untuk mencari pengaruh perlakuan tertentu terhadap yang lain dalam kondisi yang terkendalikan. Dalam penelitian ini, populasi yang diambil adalah kabel jenis NYM yang di beli oleh peneliti.

Sampel dalam penelitian ini adalah semua dari kabel jenis NYM dengan kabel merk A yang telah berstandar SNI dan kabel merk B yang tidak berstandar SNI. Masing-masing merk kabel memiliki panjang 1 meter dengan berbeda penampang yaitu $2 \times 1,5 \mathrm{~mm}^{2}, 3 \times 1,5 \mathrm{~mm}^{2}$, dan $3 \times 2,5 \mathrm{~mm}^{2}$.

Adapun tahapan-tahapan yang dilakukan dalam penelitian ini :
Tabel 3.1 Spesifikasi Kabel Pengujian

\begin{tabular}{|c|c|c|c|c|c|c|c|c|c|c|c|c|}
\hline \multirow{2}{*}{$\begin{array}{l}\text { Noof } \\
\text { cores. }\end{array}$} & \multirow{2}{*}{ Size } & \multicolumn{3}{|c|}{ Condictor } & \multicolumn{2}{|c|}{ Nominal Thicksess } & \multirow{2}{*}{$\begin{array}{l}\text { Approx Orevall } \\
\text { Dimmeter }\end{array}$} & \multirow{2}{*}{$\begin{array}{c}\text { Approx } \\
\text { Net Weight }\end{array}$} & \multicolumn{2}{|c|}{ Resintace at $200^{\circ} D C$} & \multirow{2}{*}{$\begin{array}{c}\text { Current Curying } \\
\text { Capacity }\end{array}$} & \multirow{2}{*}{$\begin{array}{c}\text { Tet Voltage } \\
\text { AC }\end{array}$} \\
\hline & & D & $\begin{array}{c}\text { Consturtion } \\
\text { nat }\end{array}$ & $\begin{array}{l}\text { No. of } \\
\text { wires }\end{array}$ & Insulation & Sheath & & & $\begin{array}{c}\text { Max. } \\
\text { Conducior }\end{array}$ & $\underset{\substack{\text { Nin } \\
\text { Irsulation }}}{ }$ & & \\
\hline. & $\mathrm{min}^{2}$ & $\min ^{2}$ & & & $\min$ & min & $\mathrm{mm}$ & $\mathrm{Kg} / 10 \mathrm{~mm}$ & Olmlm & MOlmim & Ampere & KV \\
\hline 2 & 1.5 & 1.4 & $\mathrm{re}(\mathrm{m}$ (m) & 177 & 0.76 & 1.2 & 8.6 & 11.8 & 12.1 & 50 & 19 & 2 \\
\hline 2 & 25 & 1.8 & $\mathrm{re}(\mathrm{mm})$ & 177 & 0.86 & 1.2 & 9.8 & $\begin{array}{l}16.2 \\
16 .\end{array}$ & 7.28 & 50 & 25 & 2 \\
\hline 2 & 4 & 2.25 & $\mathrm{re}(\mathrm{mm})$ & 177 & 0.87 & 1.2 & 10.9 & 21.5 & 4.56 & 50 & 34 & 2 \\
\hline 2 & 6 & 2.76 & $\mathrm{Ir}(\mathrm{min})$ & 177 & 0.9 & 1.3 & 122 & 18.6 & 3.03 & 50 & 44 & 2 \\
\hline 2 & 10 & 3.56 & $\mathrm{re}(\min )$ & 177 & 1.07 & 1.6 & 15 & 45 & 1.61 & 30 & 61 & 2 \\
\hline 2 & 16 & $1.7 \mathrm{x} 7$ & $\mathrm{re}(\mathrm{mm})$ & 177 & 1.14 & 1.6 & 17 & 53 & 1.15 & 40 & 82 & 2 \\
\hline 2 & 25 & $2.13 \times 7$ & $\mathrm{re}(\mathrm{mm})$ & 177 & 1.27 & 1.6 & 20.7 & 96 & 0.73 & 40 & 108 & 2 \\
\hline 3 & 1.5 & 1.4 & $\mathrm{Ie}(\mathrm{min})$ & 177 & 0.76 & 1.2 & 9.2 & 14.2 & 12.1 & 50 & 19 & 2 \\
\hline 3 & 2.5 & 1.8 & $\mathrm{rr}(\mathrm{mm})$ & 177 & 0.86 & 1.2 & 10.4 & 19.5 & 7.28 & 50 & 25 & 2 \\
\hline 3 & 4 & 2.25 & $\begin{array}{l}\mathrm{re}(\mathrm{mm}) \\
\mathrm{m}\end{array}$ & 177 & 0.87 & 1.2 & 11.6 & 26.7 & 4.56 & 50 & 34 & 2 \\
\hline 3 & 6 & 2.76 & $\mathrm{re}(\min )$ & 177 & 0.9 & 1.3 & 13.2 & 36.5 & 3.03 & 50 & 44 & 2 \\
\hline 3 & 10 & 3.56 & $\mathrm{re}(\min )$ & 177 & 1.07 & 1.6 & 16 & 36 & 1.61 & 50 & 61 & 2 \\
\hline 3 & 16 & 1.787 & $\mathrm{Ir}(\mathrm{mIII})$ & 177 & 1.14 & 1.6 & 18.5 & 82 & 1.15 & 40 & 82 & 2 \\
\hline 3 & 25 & $2.13 \times 7$ & $\mathrm{Ie}(\mathrm{mm})$ & 177 & 1.27 & 1.6 & 223 & 123 & 0.73 & 40 & 108 & 2 \\
\hline 4 & 15 & 1.4 & $\mathrm{re}(\mathrm{mm})$ & 177 & 0.76 & 1.2 & 10 & 17.5 & 12.1 & 50 & 19 & 2 \\
\hline 4 & 2.5 & 1.8 & If(min) & 177 & 0.86 & 1.2 & 11.3 & 24 & 7.28 & 50 & 25 & 2 \\
\hline 4 & 4 & 2.25 & $\mathrm{Ie}(\mathrm{min})$ & 177 & 0.87 & 1.2 & 139 & 37.5 & 4.56 & 50 & 34 & 2 \\
\hline 4 & 6 & 2.76 & $\mathrm{I}(\mathrm{mm})$ & 177 & 09 & 1.3 & 144 & 45 & 3.03 & 50 & 4 & 2 \\
\hline 4 & 10 & 3.56 & $\mathrm{Ir}(\mathrm{mm})$ & 177 & 1.07 & 1.6 & 17 & 68 & 1.61 & 50 & 61 & 2 \\
\hline 4 & 16 & 1.777 & $\mathrm{IR}(\mathrm{IIII})$ & 177 & 1.14 & 1.6 & 20.5 & 104 & 1.15 & 40 & 82 & 2 \\
\hline 4 & 25 & $2.13 \times 7$ & $\mathrm{Ir}(\mathrm{mm})$ & 177 & 1.27 & 1.6 & 25 & 160 & 0.73 & 40 & 108 & 2 \\
\hline 5 & 15 & 1.4 & $\mathrm{re}(\mathrm{mm})$ & 177 & 0.76 & 1.2 & 12.7 & 19.5 & 12.1 & 50 & 19 & 2 \\
\hline 5 & 25 & 1.8 & $\mathrm{IV}(\mathrm{mIII})$ & 177 & 0.86 & 1.2 & 14.1 & 28 & 7.28 & 50 & 25 & 2 \\
\hline$\xi$ & 4 & 2.25 & $\mathrm{Ie}(\mathrm{min})$ & 177 & 0.87 & 1.2 & 16.9 & 42.6 & 4.36 & 50 & 34 & 2 \\
\hline 5 & $\begin{array}{l}7 \\
6\end{array}$ & 2.76 & $\mathrm{re}(\mathrm{mml})$ & $\begin{array}{l}177 \\
17\end{array}$ & $\begin{array}{l}0.87 \\
0.9\end{array}$ & 1.3 & 18.8 & 58.4 & $\begin{array}{l}3.0 \\
3.03\end{array}$ & 50 & 4 & 2 \\
\hline 5 & 10 & 3.56 & $\mathrm{Ir}(\mathrm{mm})$ & 177 & 1.07 & 1.6 & 19.5 & 87.6 & 1.61 & 50 & 61 & 2 \\
\hline 5 & 16 & $1.7 \times 7$ & $\mathrm{re}(\mathrm{mm})$ & $\begin{array}{l}177 \\
\text {. }\end{array}$ & 1.14 & $\begin{array}{l}1.6 \\
10\end{array}$ & 23 & 130 & 1.15 & 40 & 82 & 2 \\
\hline 5 & 25 & 2.1387 & $\mathrm{Ie}(\min )$ & 177 & $\begin{array}{l}1.27 \\
1.27\end{array}$ & $\begin{array}{l}1.6 \\
\end{array}$ & 28 & 199 & 0.73 & 40 & 108 & 2 \\
\hline
\end{tabular}

Sumber: SNI 04-2699: 1999

Alat ukur yang digunakan dalam penelitian ini adalah sebagai berikut :

1. Rangkaian beban lampu, digunakan untuk memberikan besaran arus yang berbeda

2. Chamber pengujian, digunakan untuk memberikan kondisi suhu $25^{\circ} \mathrm{C}-70^{\circ} \mathrm{C}$

3. Mili Ohm meter, digunakan untuk mengukur tahanan penghantar

4. Infrared Thermometer, digunakan untuk mengukur suhu penghantar

5. Stopwatch, digunakan untuk menghitung waktu pengujian.

6. Digital Clamp meter, digunakan untuk mengukur besaran arus pada rangkaian beban.

Pengujian bertujuan untuk mengukur nilai suhu penghantar, tahanan penghantar dengan pengaruh peningkatan suhu dan besaran arus, dan melihat nilai tahanan penghantar sesuai dengan standar yang telah ditetapkan oleh Standar Perusahaan Listrik Negara (SPLN) dan SNI.

Tempat pelaksanaan pengujian di Laboratorium Pusat Penelitian Sistem Mutu dan Teknologi Pengujian LIPI. Berikut langkahlangkah melakukan pengujian:

Prosedur pengujian kabel pada suhu chamber pengujian $25-70{ }^{\circ} \mathrm{C}$ sesuai dengan variasi arus yang ditentukan.

1. Menyalakan sumber AC $220 \mathrm{~V}, 50 \mathrm{~Hz}$ untuk rangkaian beban

2. Menyalakan rangkaian beban dan mengatur arus keluaran sesuai dengan variasi pengujian yang diinginkan. 
3. Mengukur arus listrik pada kabel penghantar yang dialiri besaran arus menggunakan digital clamp

4. Setiap 10 menit dari satu jam waktu pengujian, lepas rangkaian beban.

5. Mencatat suhu penghantar kabel setelah diberikan perlakuan peningkatan suhu dan besaran arus.

6. Mengukur tahanan penghantar menggunakan miliohmmeter, dengan sumber tegangan dimatikan terlebih dahulu. Adapun rangkaian pengujian sebagai berikut:

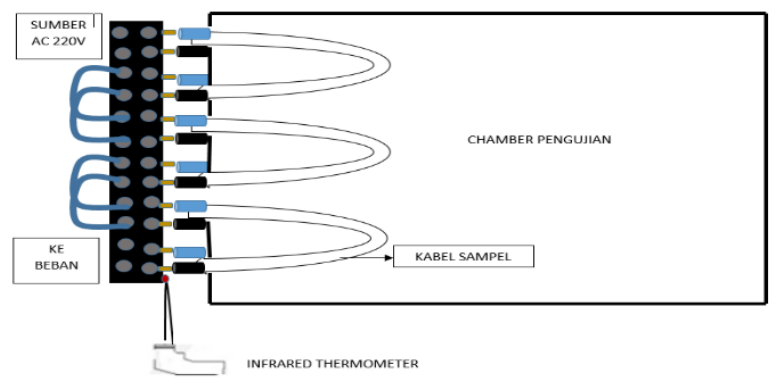

Gambar 3.1 Rangkaian Pengujian Suhu Penghantar

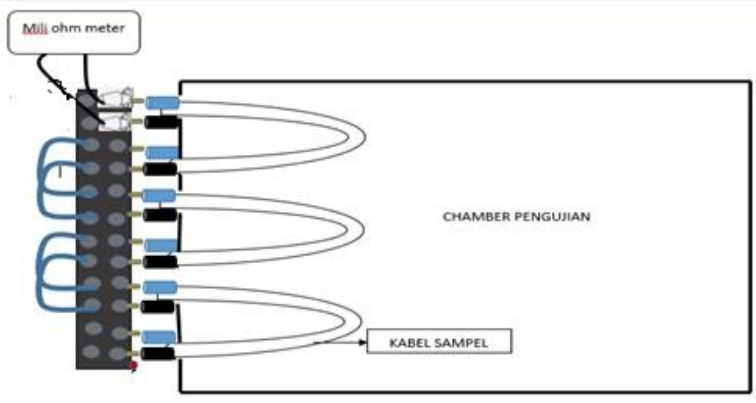

Gambar 3.2 Rangkaian Pengujian Tahanan Penghantar

\section{HASIL DAN PEMBAHASAN Hasil Pengujian Suhu Penghantar Merk A dan B}

Setelah dilakukan pengujian, pengaruh peningkatan suhu chamber dan besaran arus dapat meningkatkan nilai suhu penghantar dan tahanan penghantar.

Selanjutnya tahanan penghantar dapat dihitung menggunakan persamaan :

$R_{t}=R_{o}\left(1+\alpha_{0} \mathrm{t}\right)$

$R_{t}=$ tahanan penghantar pada $\mathrm{t}^{\circ} \mathrm{C}$

$R_{0}=$ tahanan penghantar pada $0^{\circ} \mathrm{C}$

$\alpha_{0}=$ koefisien suhu tahanan per ${ }^{\circ} \mathrm{C}$ pada $0{ }^{\circ} \mathrm{C}$

$\mathrm{t}=\mathrm{suhu}^{\circ} \mathrm{C}$

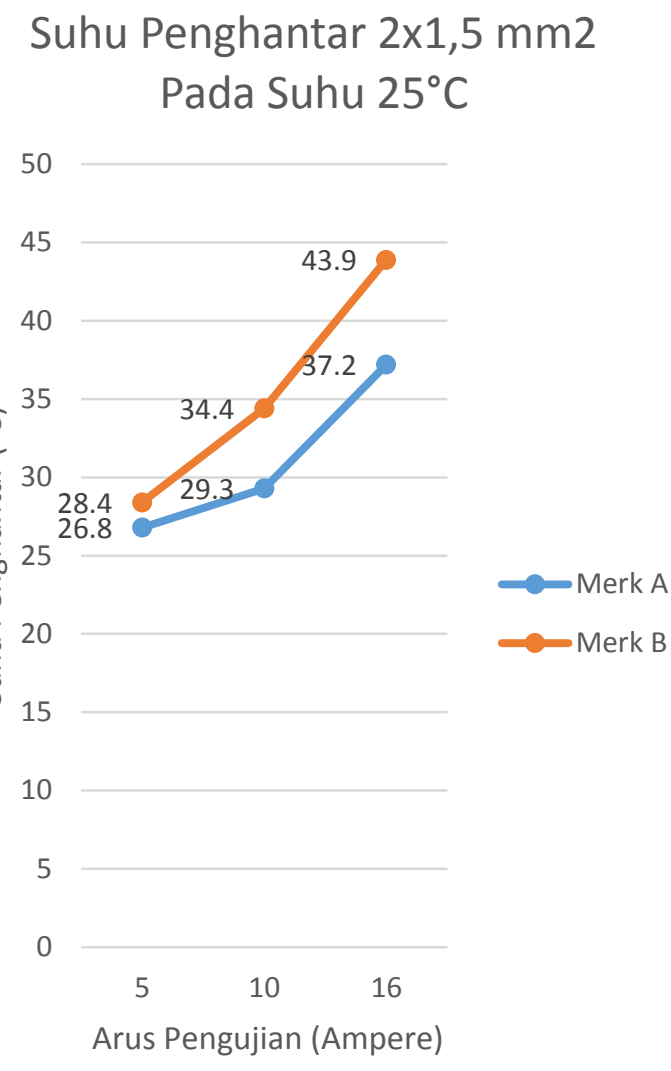

Gambar 4.1 Grafik Suhu Penghantar 2x1,5 mm² Arus 5A Berdasarkan Peningkatan Suhu

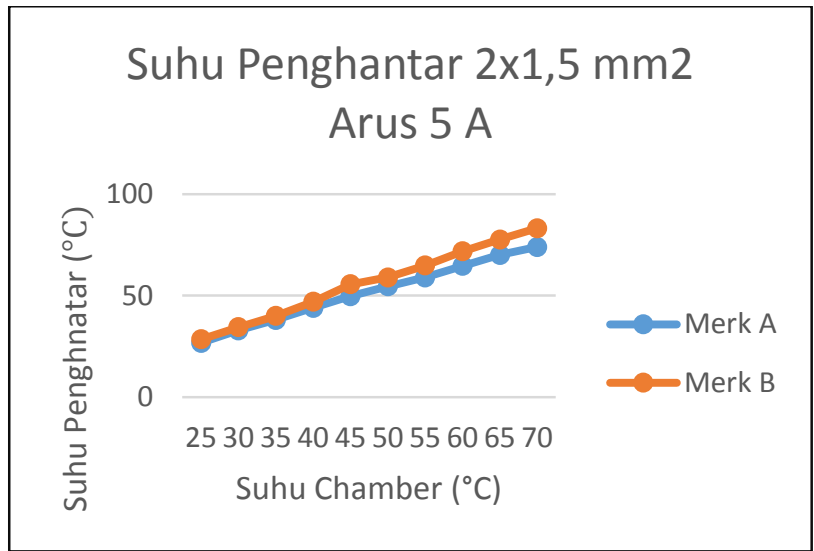

Gambar 4.2 Grafik Suhu Penghantar 2x1,5 mm Arus 5A Berdasarkan Besaran Arus

Dari data pengujian didapat dengan pengaruh peningkatan suhu chamber, penghantar kabel listrik merk B. Sesuai dengan grafik 4.1, nilai suhu penghantar meningkat lebih besar dibandingkan dengan suhu penghantar pada penghantar kabel listrik merk A. Peningkatan suhu di chamber termasuk sumber panas dari lingkungan luar yang dapat mempengaruhi peningkatan nilai suhu penghantar pada penghantar kabel listrik. Sesuai dengan grafik 
4.2, semakin besar arus maka semakin besar kenaikan suhunya. Besarnya suhu pada penghantar kabel listrik yang terjadi disebabkan oleh besarnya rugi-rugi panas yang terjadi.

Hubungan antara suhu dan waktu dari keadaan transien sampai setimbang dapat ditunjukkan pada persamaan 4.1, dimana semakin tinggi kesetimbangannya, maka kenaikan suhu yang dialami juga semakin besar.

$$
\Delta T=\Delta T_{\mathrm{m}}\left(1-e^{-t / \tau_{t}}\right) \ldots \ldots(4.1)
$$

$\Delta T \quad=$ kenaikan suhu $\left({ }^{\circ} \mathrm{C}\right)$

$\Delta T_{\mathrm{m}} \quad=$ kondisi suhu setimbang $\Delta T_{\mathrm{m}}=\mathrm{q} \cdot \mathrm{R}_{\mathrm{T}}$

$\mathrm{t} \quad=$ waktu $(\mathrm{s})$

$\tau_{t} \quad=$ termal time-constant

Semakin besar kenaikan suhu maka semakin besar pula resistansi termalnya, sesuai dengan persamaan 4.2

$$
\Delta T_{\mathrm{m}}=\mathrm{q} \cdot \mathrm{R}_{\mathrm{t}}
$$

Dimana $\Delta T$ merupakan kenaikan suhu, $q$ adalah aliran panas, dan $R_{t}$ adalah resistansi termal.

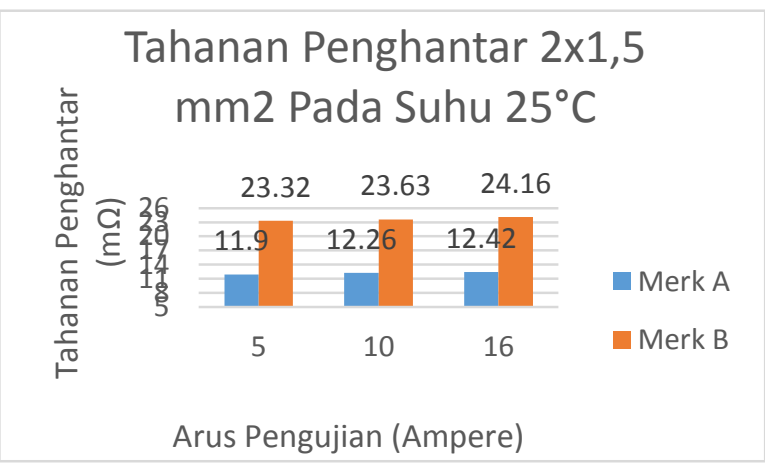

Gambar 4.3 Grafik Tahanan Penghantar 2x1,5 $\mathrm{Mm}^{2}$ Arus 5A Berdasarkan Peningkatan Suhu

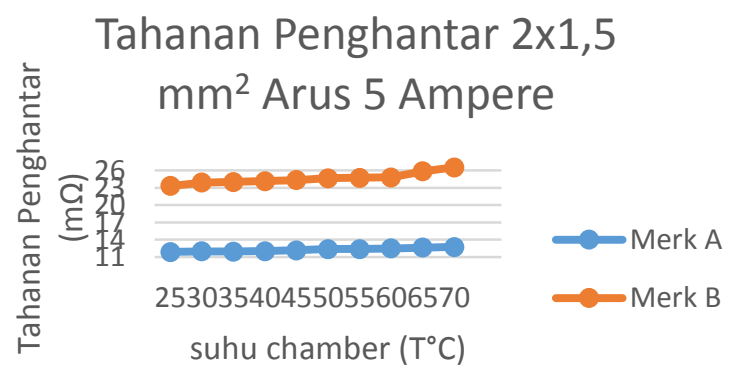

Gambar 4.4 Grafik TahananPenghantar 2x1,5 $\mathrm{Mm}^{2}$ Arus 5A Berdasarkan Peningkatan Suhu

\section{Tahanan Penghantar Merk A Arus 5 Ampere}

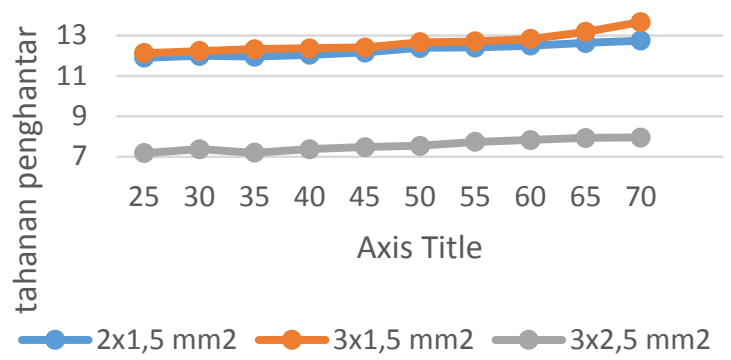

Gambar 4.5 Grafik Tahanan Penghantar Arus 5A Berdasarkan Peningkatan Suhu

Berdasarkan grafik 4.4, dihasilkan bahwa setiap kenaikan arus yang dialirkan nilai tahanan penghantar semakin meningkat. Dimana dapat dijelaskan dengan persamaan 4.3 :

$$
\mathrm{R}=\frac{I}{V}
$$

Dengan : $\mathrm{R}=$ resistansi atau tahanan $(\mathrm{ohm} / \Omega)$

$\mathrm{I} \quad=$ arus yang mengalir $(\mathrm{A})$

Berdasarkan persamaan diatas bahwa nilai tahanan penghantar akan semakin meningkat dengan meningkatnya besaran arus yang dialirkan di penghantar tersebut.

Berdasarkan grafik 4.3 dan 4.5, adanya kenaikan suhu yang bersumber dari panas aliran arus listrik dan panas pada chamber menyebabkan meningkatnya nilai tahanan penghantar kabel listrik. Sesuai dengan hubungan antara suhu (T) dan $\mathrm{R}$ tahanan penghantar (R). Luas penampang penghantar kabel listrik memiliki pengaruh terhadap nilai tahanan penghantar, yaitu semakin besar luas penampang penghantar maka nilai penghantar kabel listrik akan semakin kecil, sesuai dengan hubungan antara luas penampang (A) dan tahanan penghantar (R). Jika luas penampang penghantar kabel listrik kecil dan suhu penghantar mengalami kenaikan maka berpengaruh besar terhadap kenaikan nilai tahanan penghantar kabel listrik tersebut, yaitu hubungan antara luas penampang (A), tahanan penghantar $(\mathrm{R})$, dan suhu $(\mathrm{T})$. dapat dilihat pada persamaan 2.3 dan 2.4 sebagai berikut :

$$
\begin{aligned}
& R_{t}=R_{O}\left(1+\alpha_{0} \mathrm{t}\right) \ldots \quad(2.3) \\
& \mathrm{R}=\rho \frac{L}{A} \ldots \ldots \ldots \ldots \ldots \\
& \mathrm{R} \quad=\text { tahanan penghantar }(\Omega) \\
& \rho \quad=\text { resistivitas bahan }(\Omega \mathrm{m})
\end{aligned}
$$


$L \quad=$ panjang penghantar $(\mathrm{m})$

$A \quad=$ luas penampang penghantar $\left(\mathrm{mm}^{2}\right)$

\section{KESIMPULAN DAN SARAN \\ Kesimpulan}

1. Peningkatan suhu chamber dapat meningkatkan besarnya nilai suhu penghantar kabel listrik $2 \times 1,5 \mathrm{~mm}^{2}, 3 \times 1,5$ $\mathrm{mm}^{2}$ dan $3 \times 2,5 \mathrm{~mm}^{2}$. Saat arus pengujian $5 \mathrm{~A}$ dan peningkatan suhu chamber $25^{\circ} \mathrm{C}-70^{\circ} \mathrm{C}$, nilai suhu penghantar $2 \times 1,5 \mathrm{~mm}^{2}$ mengalami kenaikan sebesar $6,8 \%$ dan $11,2 \%$ dengan nilai $26,7^{\circ} \mathrm{C}$ dan $27,8^{\circ} \mathrm{C}$, meningkat sampai dengan $74^{\circ} \mathrm{C}$ dan $82,9^{\circ} \mathrm{C}$ dengan persentase kenaikan sebesar 5,71\% dan 18,43\%. Pada variasi suhu yang lain setiap kenaikan suhu chamber maka nilai suhu penghantar akan meningkat di masing-masing variasi penampang penghantar kabel.

2. Peningkatan suhu chamber dapat meningkatkan nilai tahanan penghantar kabel listrik $2 \times 1,5 \mathrm{~mm}^{2}, 3 \times 1,5 \mathrm{~mm}^{2}$ dan $3 \times 2,5 \mathrm{~mm}^{2}$. Saat arus pengujian $5 \mathrm{~A}$ dan peningkatan suhu chamber $25^{\circ} \mathrm{C}-70^{\circ} \mathrm{C}$, nilai tahanan penghantar 2 x $1,5 \mathrm{~mm}^{2}$ mengalami kenaikan sebesar $9,07 \%$ da dengan nilai $11,90 \mathrm{~m} \Omega$ dan 23,32 $\mathrm{m} \Omega$, nilai koreksi antara perhitungan dan pengukuran adalah $6,25 \%$ dan $6,48 \%$, meningkat sampai dengan $16,77 \%$ dan 26,91 $\%$ dengan nilai sebesar $12,74 \mathrm{~m} \Omega$ dan 26,55 $\mathrm{m} \Omega$, nilai persentase koreksi pengukuran sebesar 3,61 \% dan 1,76 \%. Data hasil pengujian sesuai dengan hubungan tahanan penghantar akan ber ubah dengan perubahan suhu.

\section{Saran}

Berdasarkan hasil penelitian ini, terdapat beberapa saran yang dapat dilakukan untuk penelitian lebih lanjut, yaitu:

1. Penelitian pada luas penampang penghantar kabel listrik perlu dilakukan dengan variasi penampang penghantar kabel listrik yang lain. Sehingga dapat dilakukan jenis pengujian penampang penghantar kabel listrik yang berbeda untuk penelitian selanjutnya.

2. Perlu menambahkan variasi untuk besaran arus pengujian untuk mengetahui kuat hantar arus pada penghantar kabel listrik tersebut. Sehingga dapat dimanfaatkan untuk mengetahui penggunaan kabel listrik sesuai dengan kebutuhan.

3. Pada jenis sampel merk kabel listrik perlu dilakukan pengujian dengan merk yang lain, agar mendapatkan nilai tahanan penghantar yang terbaik sehingga nilai tahanan penghantar yang sesuai standar dan penyaluran daya listrik menjadi effisien.

\section{DAFTAR PUSTAKA}

Almanda, Deni dan Anwar Ilmar Ramadhan. (2014). Evaluasi Perbandingan Kabel NYM 3 X 1,5 $\mathrm{Mm}^{2}$ Merk A Dan B Di Tinjau Dari Tahanan Panas Isolasi Kabelnya. Jurnal Seminar Nasional Sains dan Teknologi, 2014 1-8.

Cekdin, Cekmas dkk. (2013). Rangkaian Listrik. Penerbit: CV AndiOffset. Yogyakarta.

F.A.Y Walangare, dkk. (2013). Pemrograman Perhitungan Termis Kabel Bawah Tanah 20 kV Menggunakan Program Visual Basic 6.0. eJurnal Teknik Elektro dan Komputer: Unsrat, Manado, 2013 1-11.

Faizal, Rukdas Imam. 2009. Analisis Temperatur Kabel Terhadap Penekukan Dan Besar Arus. [skripsi]. Depok: Departemen Teknik Elektro, Universitas Indonesia.

Falcon, Rafael. (2008). Analisis Karakteristik Termal Dan Resistansi Penghantar Pada Kabel Inti Ganda NYM 2 × 1,5 $\mathrm{mm}^{2}$ [skripsi]. Depok: Departemen Teknik Elektro, Universitas Indonesia

Frank P. Incropera, dkk. (2006). Fundamentals of Heat and Mass Transfer. Peneribit: Library of Congress Cataloging-in Publication Data: United State of America.

G.J, Anders. 1997. Rating of Electric Power Cables : Ampacity Computations for Transmission, Distribution, and Industrial Applications Institute of Electrical and Electronics Engineers Inc. New York.

Luthfi, Ahmad Mohajir. Perhitungan Termis dan Kemampuan Hantar Arus Kabel Bawah Tanah $20 \mathrm{kV}$ pada PT PLN (Persero) Area Pontianak. Jurnal Fakultas Teknik Universitas Tanjungpura, 1-8.

Setiabudy, Rudy. (2007). Material Teknik Listrik. UI-Press : Jakarta.

SNI 04-3893-1995 : Metode Pengujian Kabel Listrik. 
SNI 04-6629.2-2006 : Kabel Berinsulasi PVC dengan Tegangan Pengenal sampai 450/750 V Bagian 2 : Metode Uji.

SNI 04-6629.1-2006 : Kabel Berinsulasi PVC dengan Tegangan Pengenal sampai 450/750 V Bagian 1 : Persyaratan Umum

Standar Perusahaan Umum Listrik Negara. "Kabel berisolasi dan berselubung PVC tegangan pengenal 300/500 Volt (NYM)". Jakarta : SPLN 42-2 :1992.

Sugiyono. 2015. Metode Penelitian Pendidikan (Pendekatan Kuantitatif, Kualitatif, dan R\&D). Penerbit CV. Alfabeta: Bandung.

Sutrisno dan Tak Ik Gie. 1979. Seri Fisika (Fisika Dasar). Penerbit ITB: Bandung.

Thue, Williamm. 1999. Electrical Power Cable Engineering. Macelf Dekker Inc. New York.

Thue, Williamm. 2012. Electrical Power Cable Engineering Third Edition. Penerbit Taylor and Francis Group. New York 